\title{
Crohn's disease and diffuse symmetrical periostitis
}

\author{
G. NEALE, A. R. KELSALL, AND F. H. DOYLE \\ From Watford General Hospital and the Departments of Medicine and Radio-diagnosis, \\ Royal Postgraduate Medical School, London
}

\begin{abstract}
Although in many textbooks (Lipman and Massie, 1960; MacBryde, 1965; Shulman, 1966) Crohn's disease is listed among the causes of hypertrophic osteoarthropathy an extensive search of the literature has failed to reveal an adequately documented case.

We report here a 17-year-old boy who has diffuse Crohn's disease of the small and large intestine associated with marked periosteal new bone formation and mild clubbing of the fingers.
\end{abstract}

\section{CASE REPORT}

In 1966, a 17-year-old English schoolboy (R.W.) was admitted to the Metabolic Unit, Hammersmith Hospital, for the investigation of oedema and hypoproteinaemia without proteinuria. His illness began five years before with a perianal abscess. He developed an anal fistula and intermittent diarrhoea. Tuberculosis was suspected but acid-fast bacilli could not be found either by direct examination or by culture of pus taken from the fistula. There was no response to three months' treatment with Pasinah-302 (12 g sodium aminosalicylate; $300 \mathrm{mg}$ isoniazid per day). A surgical biopsy of the fistulous track showed granulomata typical of Crohn's disease (Dr B. Morson). The anal lesions healed spontaneously over the next two months and the patient was well for two and a half years. Subsequently, for the next two years he had intermittent diarrhoea (three or four bowel actions a day) and noticed occasional ankle swelling. During the five years of his illness he grew rapidly in height (from $5 \mathrm{ft} 3$ in. to $6 \mathrm{ft} 1 \frac{1}{2}$ in.) but his weight remained constant. His parents noticed that his limbs became disproportionately long during this period of rapid growth (Fig. 1). There was no history of bone or joint pain.

CLINICAL EXAMINATION He was very thin and had slight ankle oedema. His height was $185 \mathrm{~cm}$ (crown-pubis $85.5 \mathrm{~cm}$, pubis-heel $99.5 \mathrm{~cm}$ ), span $185 \mathrm{~cm}$, and weight $50.5 \mathrm{~kg}$. His facial appearance was distinctive, with a malar flush and a prominent lower lip. His skin was soft and normal with no evidence of hyperhydrosis or of overactivity of the sebaceous glands. The fingers were mildly clubbed. Limb movements were full and pain-free but small effusions were noted in both knee joints on one occasion. In infancy an accessory digit had been removed from the left hand (his father and sister also had had accessory digits). His arms and legs were disproportionately long compared with his trunk (Fig. 1).
The blood pressure was $105 / 70 \mathrm{~mm} \mathrm{Hg}$ and the heart and lungs were clinically normal. The abdomen was slightly distended and bowel sounds were active. No organs were palpable and there was no abdominal tenderness. Rectal examination revealed a small posterior fissure. The rectal mucosa was pale and slightly lumpy but it did not bleed when touched and there were no ulcers.

Sexual development was equivalent to that of an

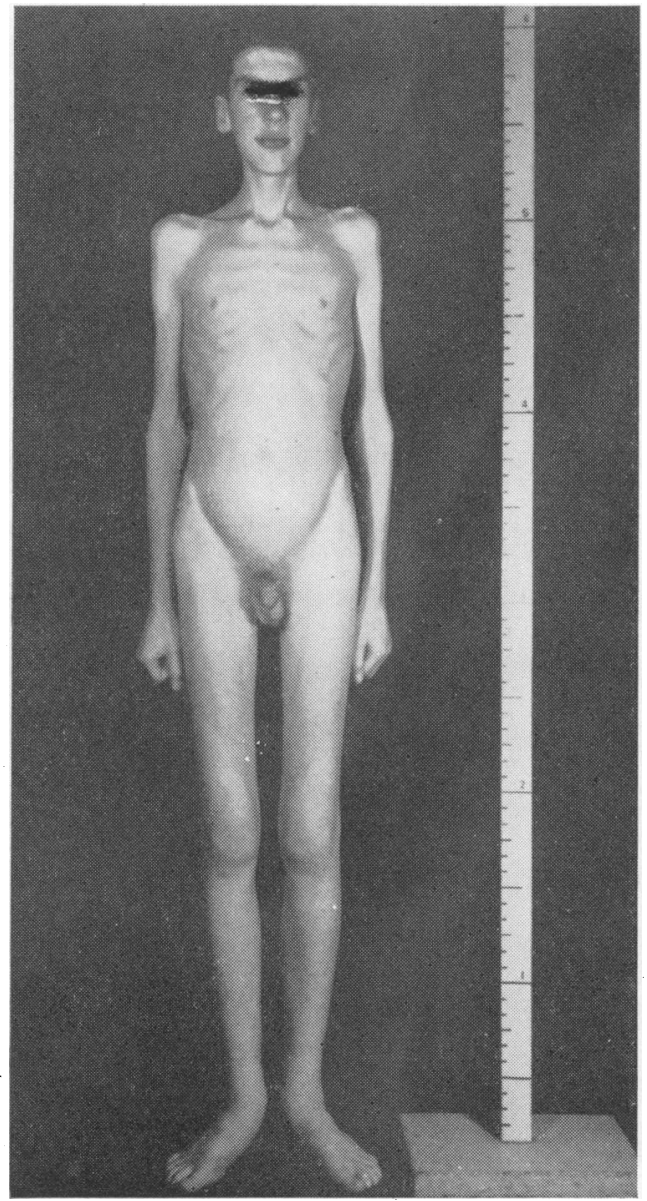

FIG. 1. R.W. General appearance showing disproportion between length of limbs and length of trunk. 
average 15-year-old boy. No abnormalities were found in the nervous system.

INVESTIGATION Haemoglobin was $10 \cdot 2 \mathrm{~g} / 100 \mathrm{ml}$, serum iron $10 \mu \mathrm{g} / 100 \mathrm{ml}$, iron-binding capacity $166 \mu \mathrm{g} / 100 \mathrm{ml}$, $\mathrm{B}_{12} 325 \mu \mu \mathrm{g} / \mathrm{ml}$, and folic acid $3.5 \mathrm{~m} \mu \mathrm{g} / \mathrm{ml}$. The blood film was markedly hypochromic and occult blood was intermittently present in the stools.

The patient was hypoalbuminaemic (serum albumin $2 \cdot 1 \mathrm{~g} / 100 \mathrm{ml}$ ) but liver function tests were normal (bromsulphthalein retention less than $5 \%$ at $45 \mathrm{~min}$ ). The hypoalbuminaemia was apparently due to proteinlosing enteropathy because $2.5 \%$ of an intravenous dose of ${ }^{131}$ I-PVP was excreted in four days (normal $<1.5 \%$ ). Serum calcium was 9.4 , phosphate $3.9 \mathrm{mg} / 100 \mathrm{ml}$, and alkaline phosphatase 10 K.A. u. per $100 \mathrm{ml}$.

Chest radiographs were normal. Arterial blood was $93 \%$ saturated with oxygen at rest, and $95 \%$ saturated after exercise.

There was no endocrine abnormality (protein-bound iodine $5 \cdot 1 \mu \mathrm{g} / 100 \mathrm{ml} ; 17$-oxygenic-steroid excretion $6.0 \mathrm{mg} / 24 \mathrm{hr}, 17$-ketosteroid excretion $14.0 \mathrm{mg} / 24 \mathrm{hr}$ ). Forty-six chromosomes were found in 27 out of 30 cultured leucocyte preparations, and the karyotype was normal male.

Gastrointestinal studies revealed mild malabsorption: faecal fat $8.0 \mathrm{~g} / 24 \mathrm{hr}$, faecal nitrogen $4.1 \mathrm{~g} / 24 \mathrm{hr}(70 \mathrm{~g}$ fat, $70 \mathrm{~g}$ protein diet); $\mathrm{B}_{12}$ absorption (Schilling test) $4 \cdot 7 \%$, xylose excretion $5 \cdot 3 \mathrm{~g}$ (of $25 \mathrm{~g}$ dose).

The jejunal mucosa was sampled with a Crosby capsule and was structurally normal apart from slight oedema and occasional distended lymphatic spaces.

RADIOLOGY A barium meal and follow-through examination showed multiple ileal strictures (Fig. 2) and a number of slightly dilated small bowel loops. Barium enema showed an abnormal colon. The contour

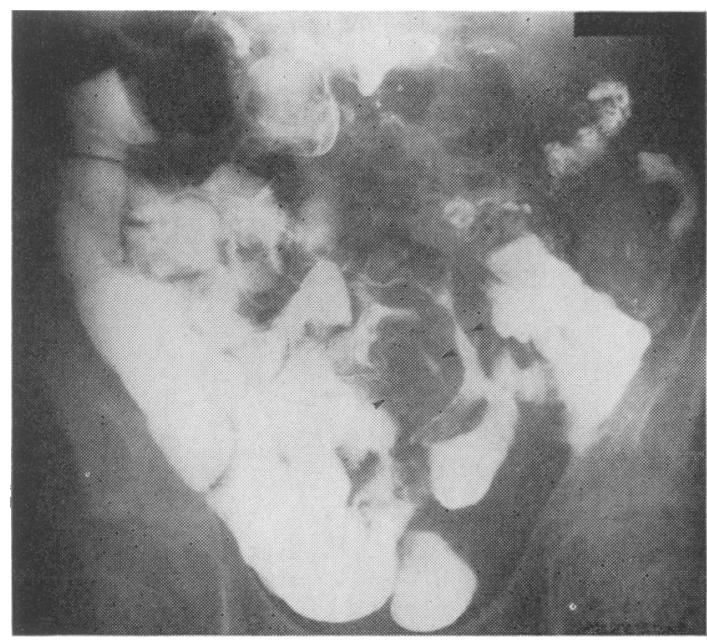

FIG. 2. Several strictures, three of which are arrowed, are apparent in the middle and distal thirds of the small bowel. of the sigmoid and lower part of the descending colon was irregular (Fig. 3). There were numerous projections of barium consistent with small ulcers, some having a 'collar-stud' appearance. The transverse and proximal descending colon was considerably dilated and showed an almost total absence of haustration. The ascending colon was extremely irritable. The small and large bowel appearances suggested widespread Crohn's disease.

Bone radiography showed a rather osteoporotic axial skeleton and a slight trefoil deformity of the pelvis. There was laminated periosteal new bone formation along the shafts of the tibiae and fibulae (Fig. 4), the proximal (Fig. 5) and distal thirds of the femoral diaphyses, the shafts of the ulnae and the distal thirds of the radial diaphyses. A small amount of new bone was seen along the distal few inches of the humeral shafts. Several of the metatarsals in both feet had marked periosteal new bone formation, but in the hands only the left index metacarpal showed a just perceptible amount of periosteal new bone along its radial margin. The skeletal age estimated by the method of Greulich and Pyle (1959) was $15 \frac{1}{2}$ years. A chest radiograph, tomography of the mediastinum, and a barium swallow showed no abnormality.

\section{COMMENT}

This case report describes a patient with severe Crohn's disease of the small and large bowel associated with widespread subperiosteal new bone formation. These findings raise two questions: (1) Are the skeletal changes similar to those described as pulmonary hypertrophic osteoarthropathy, and, (2) what is their probable aetiology?

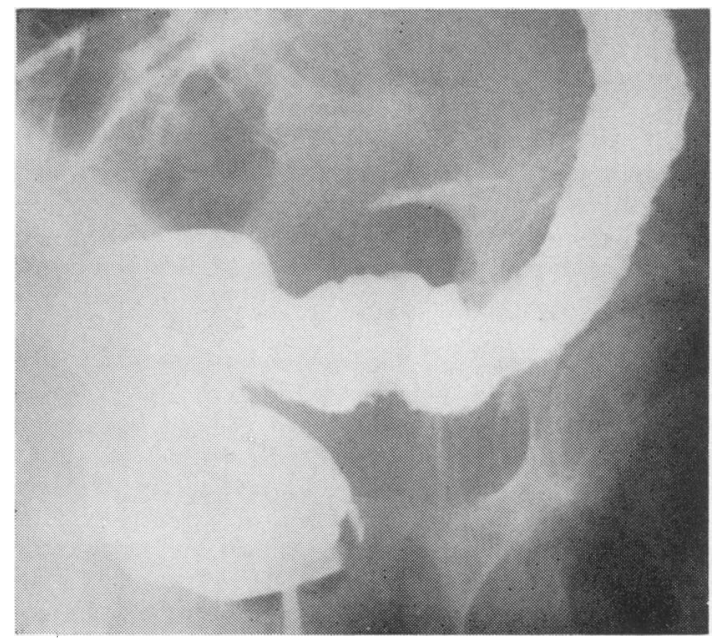

FIG. 3. The sigmoid and distal descending colon are irregular in contour. Marginal projections of barium represent ulcers seen in profile. 

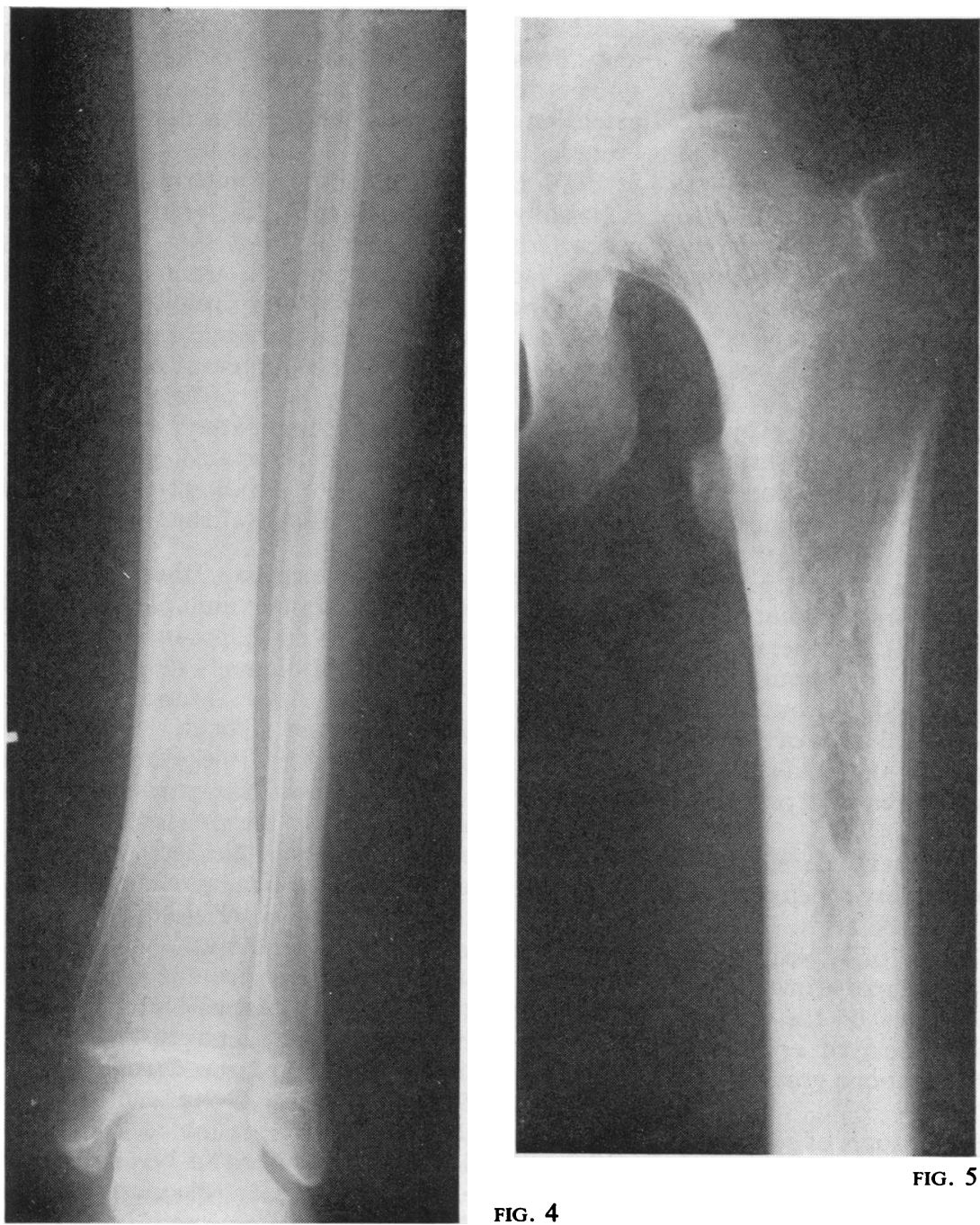

FIG. 5

FIG. 4
FIG. 4. Florid evidence of periosteal new bone along the margins of the left tibia and fibula.

FIG. 5. Multiple layers of periosteal new bone are seen along the lateral margin of the proximal third of this femoral shaft.
NATURE OF 'HYPERTROPHIC OSTEOARTHROPATHY' In 1889 von Bamberger described an overgrowth of the peripheral skeleton of some patients with chronic lung disease. A year later, Marie (1890) described the condition more fully and used the term 'pulmonary hypertrophic osteoarthropathy'. Before these two descriptions similar clinical appearances had been confused with acromegaly and osteitis deformans. The drawings published by Marie showed bony enlargement around the limb joints associated with marked clubbing of the fingers. Excess subperiosteal bone was demonstrated at necropsy.

In 1907 Alexander reviewed the subject and summarized the findings of previous workers. He stated that the essential feature of hypertrophic osteoarthropathy is a deposition of new bone along the shafts of long bones. This is secondary to another chronic disease which is usually, but not always, pulmonary in origin. If bone changes develop rapidly synovitis may occur in adjacent joints. Although clubbing of the fingers is very commonly associated it is not peculiar to the condition of secondary hypertrophic osteoarthropathy. Two further reviews of the subject have been published (Locke, 1915; Mendlowitz, 1942) in both of which hypertrophic osteoarthropathy has been considered to be an extension of the process of clubbing. There 
is, however, no good evidence to support a common pathogenetic mechanism for these two processes, one of which causes the apposition of excess periosteal bone and the other soft tissue overgrowth. In lung disease bone changes may precede the appearance of clubbing or even occur alone (Ayre, 1947) whilst in cyanotic congenital heart disease severe clubbing is very common but only rarely accompanied by bony changes (Means and Brown, 1947; Trever, 1958).

Although the patient described in this report has only a minor degree of clubbing and no arthropathy, apart from transient small effusions into the knee joints, he fits the description of secondary hypertrophic osteoarthropathy as given by Alexander (1907). Periosteal bone changes in association with pulmonary disease are variable in appearance and distribution (Compere, Adams, and Compere, 1935). In R.W. the femora, tibiae, fibulae, humeri, radii, and ulnae are all affected and lamination of new bone is well marked (Figs. 4, 5). The metatarsals show marked changes and the only surprising feature is the apparent sparing of all but one of the metacarpal bones. As with nearly all cases of secondary hypertrophic osteoarthropathy the axial skeleton and limb girdles do not show any abnormal periosteal bone (Compere et al, 1935).

Mueller (1930) has suggested that the development of periosteal new bone can lead to excess lengthening of the affected bones. This may be so in R.W. in whom photographs up to the age of 12 years show normal limb proportions. His maximal growth seems to have occurred after the onset of the Crohn's disease, which has apparently delayed epiphyseal fusion and allowed more time for bone growth.

DIFFERENTIAL DIAGNOSIS Other causes of secondary hypertrophic osteoarthropathy appear to have been excluded in R.W. He has no clinical, radiological, or laboratory evidence of heart or lung disease. Liver function is normal and radiological examination seems to have excluded an oesophageal or other intrathoracic lesion. The serological tests for syphilis were negative and the course of the illness has been quite unlike the curious self-limiting periostitis associated with a dysproteinaemia following respiratory tract infections as described by Goldbloom, Stein, Eisen, McSheffrey, Brown, and Wiglesworth (1966).

Hereditary or idiopathic pachydermoperiostitis must also be considered as a possible diagnosis. This condition, first clearly described by Touraine, Solente, and Golé (1935), usually becomes apparent shortly after puberty, and affects males more often than females. A family history is found in about $50 \%$ of cases, and a possible chromosomal defect has been described (Tzoneva-Maneva, Bosajieva, and Petrov, 1956). Skeletal radiographs show symmetrical irregular periosteal ossification with extension of bone into attached tendons and membranes. Lamination of periosteal new bone as seen in R.W. (Fig. 4) has not been described. Clubbing is usually gross and there is nearly always a characteristic thickening of the skin, particularly of the face and scalp which is usually associated with hyperhidrosis (Vogl and Goldfischer, 1962). R.W. has none of the characteristic features of the hereditary condition, his parents have normal skeletons both clinically and radiologically, and he has a normal chromosome pattern. On the other hand he does have an associated inflammatory disease which seems to be of aetiological significance in the development of the skeletal changes.

RELATIONSHIP TO BOWEL DISEASE Bowel disease is given as a cause of clubbing and periosteal new bone formation in textbooks (Lipman and Massie, 1960; MacBryde, 1965; Shulman, 1966) and review articles (von Bamberger, 1889; Marie, 1890) but well documented cases are difficult to find. The association was first noted by Teleky in 1897 when he found hypertrophic osteoarthropathy and clubbed fingers in a patient who for the previous two years had had bloody diarrhoea due to 'dysentery'. Redmond had described a similar clinical picture in 1890, but entitled the condition 'a case of acromegaly'. A search of the literature showed that most cases of so-called hypertrophic osteoarthropathy associated with bowel disease had in fact only clubbing of the fingers. There seem to be only two other cases with unequivocal bone disease. Temple and Jaspin (1948) described a 49-year-old man who had periosteal new bone formation in association with severe diarrhoea considered to be due to nontropical sprue although an exact diagnosis was not established, whilst Honska, Strenge, and Hammarsten (1957) described a 10-year-old boy with severe inflammatory disease of the colon and rectum, marked clubbing, and extensive symptomless periosteal new bone formation. He was thought to have ulcerative colitis but again the diagnosis was not proved. The patient died at home, and no necropsy was performed.

During the past year our patient has been extremely well following the administration of intramuscular iron to correct the iron deficiency. His weight has increased $7 \mathrm{~kg}$ and the ankle oedema has disappeared. The bone changes have remained unaltered.

\section{SUMMARY}

A patient with Crohn's disease for five years has 
developed marked symmetrical periosteal new bone formation. This relationship is not well documented in the medical literature and the incidence and cause of the association is unknown.

We wish to thank Professor C. C. Booth for allowing us to study this patient and for his helpful advice, and Mrs Elizabeth Pearce for performing the chromosomal analysis.

\section{REFERENCES}

Alexander, J. F. (1907). Hypertrophic pulmonary osteoarthropathy. St. Bart. Hosp. Rep., 42, 41-79.

Ayre, W. B. (1947). A case of hypertrophic osteoarthropathy. Canad. med. Ass. J., 56, 71-73.

Compere, E. L., Adams, W. E., and Compere, C. L. (1935). Generalized hypertrophic pulmonary osteoarthropathy. Surg. Gynec. Obstet., 61, 312-323.

Goldbloom, R. B., Stein, P. B., Eisen, A., McSheffrey, J. B., Brown, B. St. J., and Wiglesworth, F. W. (1966). Idiopathic periostea hyperostosis with dysproteinemia. New Engl. J. Med., 274, 873-878.

Greulich, W. W., and Pyle, S. I. (1959). Radiographic Atlas of the Skeletal Development of the Hand and Wrist, 2nd ed. Stanford University Press, Stanford, California.

Honska, W. L., Jr, Strenge, H., and Hammarsten, J. F. (1957) Hypertrophic osteoarthropathy and chronic ulcerative colitis. Gastroenterology, 33, 489-492.

Locke, E. A. (1915). Secondary hypertrophic osteo-arthropathy and its relation to simple club-fingers. Arch. intern. Med., 15, 659-713.
Lipman, B. S., and Massie, E. (1960). Clubbed fingers and hypertrophic osteoarthropathy. In Bedside Medicine, edited by I. Snapper, p. 116. Grune and Stratton, New York.

MacBryde, C. M. (1965). Signs and Symptoms, 4th ed. p. 246. Pitman, London.

Marie, P. (1890). De l'osté-oarthropathie hypertrophiante pneumique, Rev. Méd. (Paris), 10, 1-36.

Means, M. G., and Brown, N. W. (1947). Secondary hypertrophic osteoarthropathy in congenital heart disease. Amer. Heart J., 34, 262-271.

Mendlowitz, M. (1942). Clubbing and hypertrophic osteoarthropathy. Medicine (Baltimore), 21, 269-306.

Mueller, W. (1930). Über die familiäre akromeglieähnliche Skelletterkrankung. Bruns' Beitr. klin. Chir., 150, 616.

Redmond, A. (1890). A case of acromegaly. Trans. R. Acad. Med. Irel., 9, 64-66.

Shulman, L. E. (1966). In Principles of Internal Medicine, 5th ed., edited by T. R. Harrison, R. D. Adams, I. L. Bennett, W. H. Resnik, G. W. Thorn, and M. M. Wintrobe, p. 1359. McGrawHill, New York.

Teleky, L. (1897). Beiträge zur Lehre von der 'Osteoarthropathie hypertrophiante pneumique'. Wien. klin. Wschr., 10, 143-149.

Temple, H. L., and Jaspin, G. (1948). Hypertrophic osteoarthropathy. Amer. J. Roentgenol., 60, 232-245.

Touraine, A., Solente, G., and Golé, L. (1935). Un syndrome ostéodermopathique: la pachydermie plicaturée avec pachypériostose des éxtremités. Presse méd., 43, 1820-1824.

Trever, R. W. (1958). Hypertrophic osteoarthropathy in association with congenital cyanotic heart disease. Ann. intern. Med., 48, 660-668.

Tzoneva-Maneva, M. T., Bosajieva, E., and Petrov, B. (1966). Chromosomal abnormalities in idiopathic osteoarthropathy. Lancet, 1, 1000-1002.

Vogl, A., and Goldfischer, S. (1962). Pachydermoperiostosis. Amer. J. Med., 33, 166-187.

Von Bamberger, E. (1889). Case report (Protokoll der k.k. Gesellschaft der Aerzte in Wien). Wien. klin. Wschr., 2, 226. 